\title{
Correlação entre padrão facial e relação sagital entre os arcos dentários no estágio de dentadura decídua: considerações epidemiológicas
}

\author{
Omar Gabriel da Silva Filho*, Ana Paula Corrêa de Queiroz**, Fernando José Herkrath** \\ Guilherme Ferreira Bibiano Silva ***
}

\begin{abstract}
Resumo
Objetivo: A inter-relação oclusão e morfologia facial é fundamental para o diagnóstico e planejamento em ortodontia, bem como para determinação do prognóstico de tratamento. De um modo geral, a relação sagital entre os arcos dentários (Classe) tende a refletir o comportamento sagital do esqueleto facial (Padrão). O presente trabalho avalia a correlação entre as características morfológicas sagitais da face (Padrão) e da oclusão (Classe) no estágio de dentadura decídua. Metodologia: A amostra foi composta por 2009 crianças, entre 03 e 06 anos de idade, no período de dentadura decídua completa, de 20 pré-escolas do Município de Bauru - SP. Os resultados demonstraram uma correlação estreita entre o Padrão facial e a Classe. No Padrão I predominou a Classe I (62,99\%), seguida pela Classe II $(35,82 \%)$ e Classe III $(1,18 \%)$. No Padrão II, a Classe II foi predominante $(81,35 \%)$ acompanhada de uma incidência baixa de Classe I (18,64\%). No Padrão III, a Classe III estava presente em 50\% das crianças, seguida pela Classe I, em 48,64\%, e Classe II, em 1,35\%. Resultados: A expectativa se comprovou. Há uma tendência da Classe acompanhar o Padrão, desde o estágio de dentadura decídua. Isso foi mais explícito no Padrão II. Os resultados também esclarecem que a oclusão guarda alguma independência em relação ao Padrão. Conclusão: A maior heterogeneidade na distribuição das Classes ficou para os Padrões I e III. No Padrão II, as Classes se comportaram de forma mais homogênea, com mais de 80\% das crianças exibindo Classe II.
\end{abstract}

Palavras-chave: Face. Oclusão dentária. Dente decíduo. Epidemiologia.

\section{INTRODUÇÃO}

Ao longo da sua história, a ortodontia tem reverenciado a beleza facial como meta terapêutica, agregando-a à excelência oclusal. An- gle $^{3}$ associou a face ao comportamento sagital entre os arcos dentários, mediante a consagrada classificação sagital da oclusão intitulada "Classe". Estava instaurado um método clíni-

* Ortodontista do Hospital de Reabilitação de Anomalias Craniofaciais da Universidade de São Paulo (HRAC-USP). Coordenador do curso de Ortodontia Preventiva e Interceptiva da Sociedade de Promoção Social do Fissurado Lábio-Palatal (PROFIS), Bauru-SP. ** Residente do Setor de Ortodontia Corretiva do HRAC-USP, Bauru-SP.

*** Aluno do curso de aperfeiçoamento em Ortodontia Preventiva e Interceptiva da PROFIS, Bauru-SP. 
co de diagnóstico ortodôntico que unia arcos dentários e face, adotado pela elite acadêmica desde o início da especialidade. Com a incorporação da cefalometria na ortodontia, vários outros autores $5,9,12,16,29$, ainda que sob diferentes perspectivas, preocuparam-se em relacionar a oclusão com a morfologia facial. Mas se o tema é clássico, ele se converte, atualmente, na "conversa do dia", já que a ortodontia trafega na era da análise facial.

Considerar a morfologia facial no diagnóstico, planejamento e objetivo terapêutico exige a compreensão do processo do crescimento craniofacial ${ }^{1,4,6,15}$. É interessante para o ortodontista entender o que o crescimento faz pela face a partir de sua forma embriológica até a maturidade esquelética, passando pela infância e adolescência. Em termos práticos, o ortodontista necessita saber quando, qual a magnitude e em qual direção o crescimento facial vai expressarse, qual o papel da genética e dos fatores ambientais nesse potencial e, o mais importante, como é possível influenciar o esqueleto facial com o tratamento ortodôntico, para atingir resultados ótimos dentro do potencial individual de cada paciente.

Nesse contexto, torna-se imperativo identificar o comportamento da face na má oclusão, independentemente da idade em que se faz o diagnóstico. Tudo indica que, em média, a face cresce preservando sua morfologia, já que obedece a um padrão morfogenético pré-estabelecido, definido na concepção cromossômica. Dessa forma, a avaliação da configuração facial pode ser feita em crianças, a partir da dentadura decídua pronta ${ }^{10,25}$. Apesar de a maxila e a mandíbula não terem atingido sua dimensão final e terem bastante crescimento até a maturidade esquelética, admite-se que exista uma tendência para a preservação da configuração facial, ou seja, a relação espacial entre maxila e mandíbula tende a se manter constante durante o crescimento ${ }^{4,6}$. Essa tendência se repete na relação sagital entre os arcos dentários. Nesse contexto, Classe e Padrão definem-se precocemente.

A morfologia da face infante foi motivo de estudo em trabalho epidemiológico prévio ${ }^{24}$. Prestigiou-se a análise facial com o objetivo de reconhecer o comportamento da maxila e da mandíbula ao comporem a face. A face foi classificada seguindo o conceito de Padrão ${ }^{7}$ e também de acordo com os tipos faciais braquifacial, mesofacial e dolicofacial. Faces equilibradas, sem erro esquelético, portanto, foram classificadas como Padrão I, enquanto as faces portadoras de erro esquelético sagital foram classificadas como Padrão II e Padrão III. Os Padrões face longa e face curta não constaram no referido estudo por serem de difícil diagnóstico na faixa etária em questão, já que o crescimento ainda não se expressou a ponto de caracterizar a face dentro destes tipos morfológicos ${ }^{4}$. Baseandose nos resultados obtidos nesse levantamento epidemiológico, foi encontrado predomínio de crianças Padrão I $(63,22 \%)$ em relação ao $\mathrm{Pa}-$ drão II $(33,10 \%)$ e Padrão III $(3,68 \%)$. Na análise em norma frontal, houve predomínio do tipo mesofacial $(64,56 \%)$ em relação ao dolicofacial $(21,90 \%)$ e braquifacial $(13,54 \%)$. Esses resultados estão resumidos nos gráficos 1 a 4 .

Como bem sabe o ortodontista, o diagnóstico não se esgota na avaliação da forma facial. É fundamental entender o comportamento da oclusão pela leitura dos dentes mediante análise oclusal. A literatura confirma a manifestação da má oclusão desde a dentadura decídua ${ }^{11,20,27,31}$. Aliás, a má oclusão prevalece na população de crianças tanto na dentadura decídua como na dentadura mista, como demonstraram os levantamentos epidemiológicos realizados em Bauru - SP 23,27 e expressos no gráfico 5.

Contemplados o Padrão facial e a oclusão, resta saber como as Classes se comportam dentro de cada Padrão. No diagnóstico com finalidade ortodôntica, o confronto entre Classe e Padrão é fundamental para se estabelecer um 


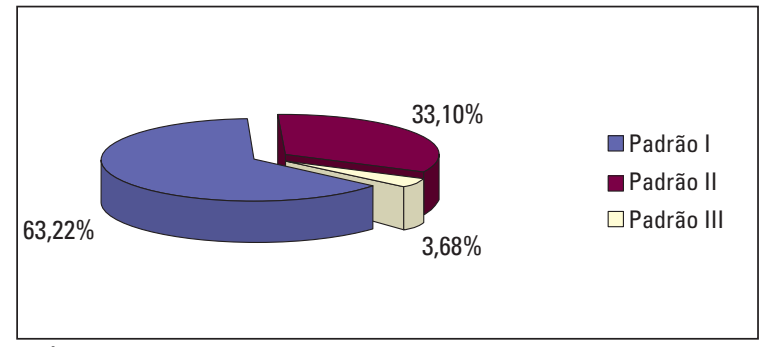

GRÁFICO 1 - Distribuição do Padrão facial sagital (Padrão I, Padrão II e Padrão III) na amostra de 2009 crianças no estágio de dentadura decídua ${ }^{24}$.

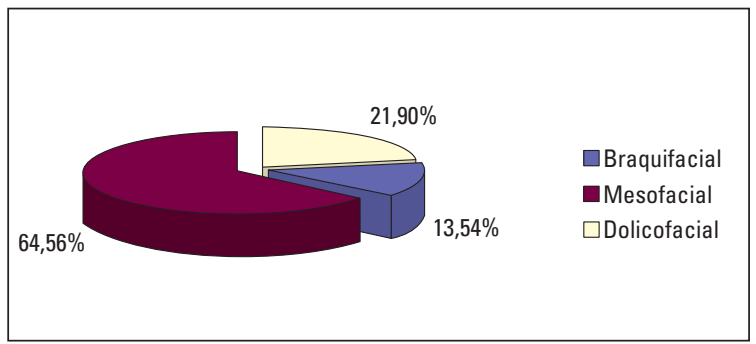

GRÁFICO 3 - Distribuição do tipo facial frontal (braquifacial, mesofacial e dolicofacial) na amostra de 2009 crianças no estágio de dentadura decídua ${ }^{24}$.

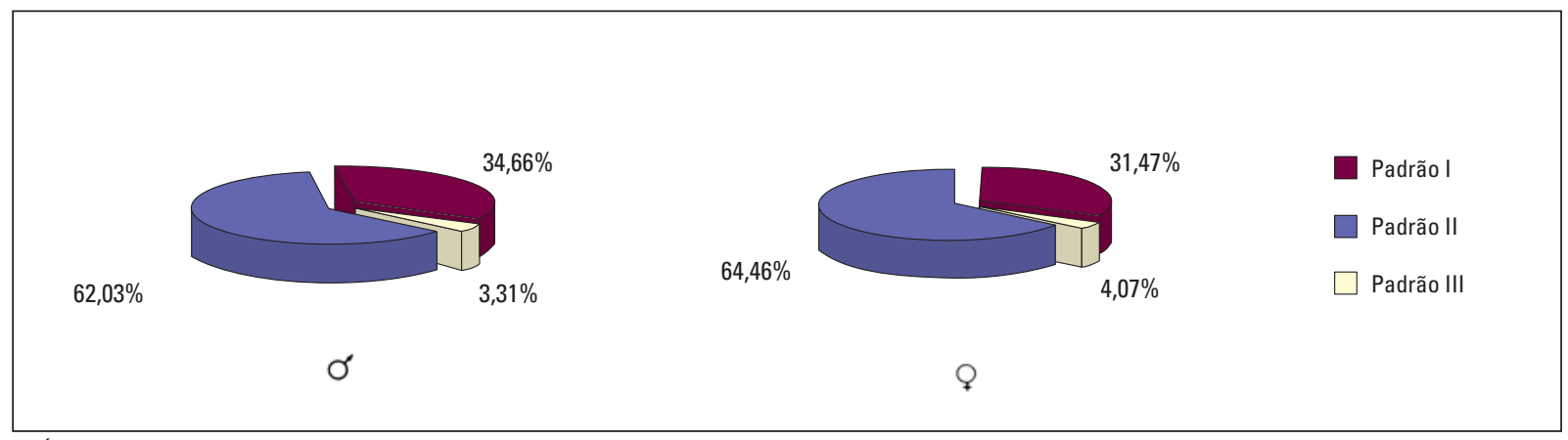

GRÁFICO 2 - Distribuição do Padrão facial sagital (Padrão I, Padrão II e Padrão III) na amostra de 2009 crianças no estágio de dentadura decídua, de acordo com $0 \operatorname{sexo}^{24}$.

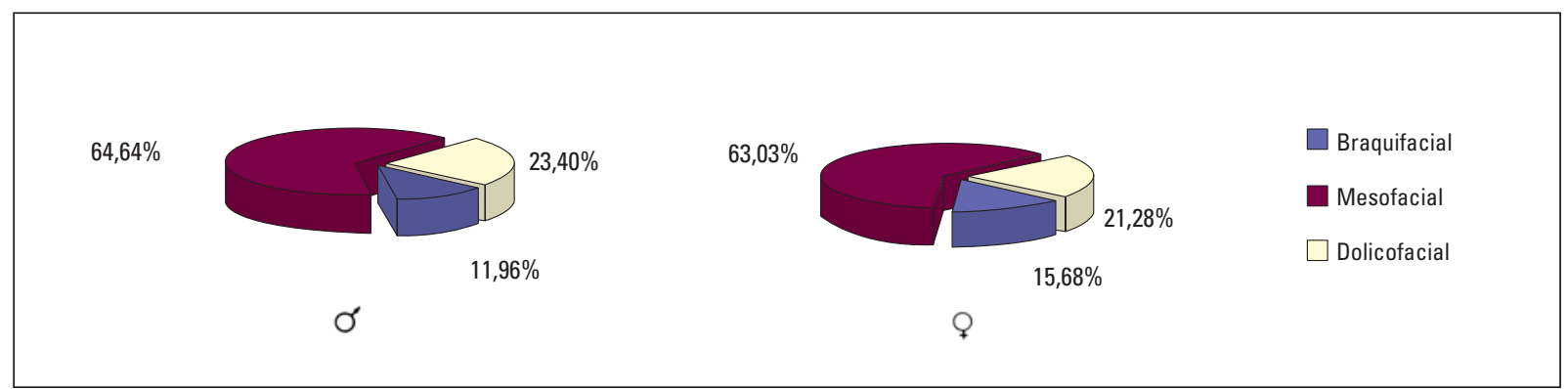

GRÁFICO 4 - Distribuição do tipo facial frontal (braquifacial, mesofacial e dolicofacial) na amostra de 2009 crianças no estágio de dentadura decídua, de acordo com $0 \operatorname{sexo}^{24}$.

planejamento coerente. Os dentes, implantados em suas bases ósseas, tendem a refletir o comportamento das bases apicais. Espera-se uma Classe I no Padrão I, uma Classe II no Padrão II, bem como uma Classe III no Padrão III. A literatura não abunda nesse assunto e ainda os estudos correlacionando bases apicais e dentes apresentam, em sua maioria, metodologia que utiliza telerradiografia em norma lateral $1^{5,10,12,16,17,18,30,32}$.
São poucos os autores que utilizaram a análise facial para estipular correlações com a disposição dos dentes, especialmente no estágio de dentadura decídua².

Dessa forma, o presente estudo epidemiológico tem por objetivo avaliar a correlação clínica entre o Padrão facial e a relação sagital entre os arcos dentários (Classe) em crianças no estágio de dentadura decídua. 


\section{MATERIAL E MÉTODOS Material}

A amostra utilizada no presente estudo foi composta por 2009 crianças, sendo 1027 do sexo masculino e 982 do sexo feminino, de etnia brasileira, entre 03 e 06 anos de idade, avaliadas em estudo anterior ${ }^{24,27}$. As crianças incluídas na amostra encontravam-se no período de dentadura decídua completa, sendo os critérios de exclusão a presença de qualquer dente permanente parcial ou totalmente irrompido e qualquer tratamento ortodôntico prévio (Tab. $1,2)$.

Todas as crianças estavam devidamente matriculadas em instituições de ensino, incluindo 12 pré-escolas públicas e 8 pré-escolas privadas, do Município de Bauru - SP, sendo as referidas escolas selecionadas de forma aleatória (Tab. 2). A visita nestas unidades foi realizada conforme autorização da Secretaria de Educação do Município de Bauru.

\section{Métodos}

O exame clínico das crianças pré-escolares foi efetuado por profissionais em formação ortodôntica, previamente calibrados, que registraram em fichas especialmente desenvolvidas as condições oclusais, bem como a morfologia facial. Os dados faciais e oclusais para a presente pesquisa foram extraídos das citadas fichas cadastrais e foram armazenados em computador.

Tabela 1 - Distribuição das 2009 crianças avaliadas no estágio de dentadura decídua, de acordo com a idade e o sexo.

\begin{tabular}{ccccc}
\hline & Masculino & Feminino & \multicolumn{2}{c}{ Total } \\
\hline Faixa etária & $(\mathrm{n})$ & $(\mathrm{n})$ & $(\mathrm{n})$ & $(\%)$ \\
$3-4$ & 232 & 238 & 470 & 23,39 \\
$4-5$ & 319 & 293 & 612 & 30,46 \\
$5-6$ & 341 & 329 & 670 & 33,34 \\
$6-7$ & 135 & 122 & 257 & 12,79 \\
Total & $1027(51,11 \%)$ & $982(48,88 \%)$ & 2009 & 100,0 \\
\hline
\end{tabular}

O exame facial de cada criança constou da análise clínica das características faciais sagitais em repouso, baseadas no conceito de Padrão7. As crianças foram posicionadas de pé e instruídas a olhar para frente, em posição natural da cabeça $^{14,19,21,22}$. O exame clínico permitiu a classificação da face em Padrão I, Padrão II e Padrão III. O Padrão I define uma boa relação sagital entre as bases apicais, com ângulo nasolabial agradável, curvatura lábio-mentoniana harmoniosa e uma linha queixo-pescoço bem definida. $\mathrm{O}$ Padrão II traduz excesso de convexidade facial, denunciada pela deficiência mandibular e/ou protrusão maxilar. O Padrão III, contrariamente, sugere perfil reto ou côncavo, denotando deficiência maxilar e/ou prognatismo mandibular.

O exame clínico intrabucal foi realizado em cadeiras comuns existentes nas escolas, sob iluminação natural e utilizando como instrumento apenas espátulas de madeira. As características oclusais consideradas aqui referem-se às condições sagitais da relação interarcos, definida pela chave de caninos como Classe I, Classe II e Classe III. O assentamento da ponta de cúspide do canino superior na ameia entre o canino e o primeiro molar decíduos inferiores determinou a relação de Classe I, situação de normalidade sagital entre os arcos dentários. Quando o canino superior fugiu dessa relação, escorregando em direção anterior, a relação interarcos foi definida como Classe II. No deslocamento do

Tabela 2 - Distribuição das 2009 crianças avaliadas no estágio de dentadura decídua, de acordo com a idade e a escola particular ou pública.

\begin{tabular}{ccccc}
\hline & Particular & Pública & \multicolumn{2}{c}{ Total } \\
\hline Faixa etária & $(\mathrm{n})$ & $(\mathrm{n})$ & $(\mathrm{n})$ & $(\%)$ \\
$3-4$ & 191 & 279 & 470 & 23,39 \\
$4-5$ & 206 & 406 & 612 & 30,46 \\
$5-6$ & 241 & 429 & 670 & 33,34 \\
$6-7$ & 164 & 93 & 257 & 12,79 \\
Total & $802(39,92 \%)$ & $1270(60,07 \%)$ & 2009 & 100,0 \\
\hline
\end{tabular}


canino superior para distal, a relação interarcos foi definida como Classe III (Fig. 1).

\section{RESULTADOS}

As 2009 crianças foram agrupadas de acordo com o Padrão facial em Padrão I (63,22\%), Padrão II $(33,10 \%)$ e Padrão III $(3,68 \%)$, conforme ilustrado no gráfico 1 .

As crianças também foram classificadas de acordo com a relação sagital entre os arcos dentários em Classe I, Classe II e Classe III. As Classes foram distribuídas dentro dos Padrões, como descrito na tabela 3 e ilustrado pelo gráfico 9 . Os gráficos 6, 7 e 8 ilustram a prevalência das Classes dentro de cada Padrão.

Os dados discriminados por sexo são descritos na tabela 4 . Na aplicação do teste quiquadrado, a distribuição das classes na amostra total e dentro de cada Padrão não foi influenciada pela variável sexo, ou seja, não foi registrado dimorfismo sexual. Portanto, os resultados serão discutidos desconsiderando a variável sexo.

Os resultados obtidos foram avaliados estatisticamente para aferir a associação entre as
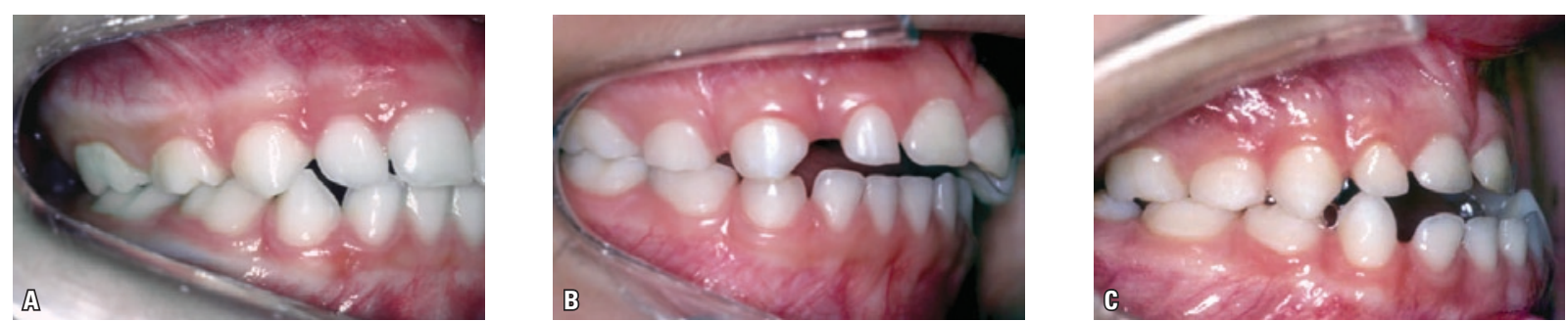

FIGURA 1 - Definição das Classes com base na relação de caninos decíduos: Classe I (A), Classe II (B) e Classe III (C).

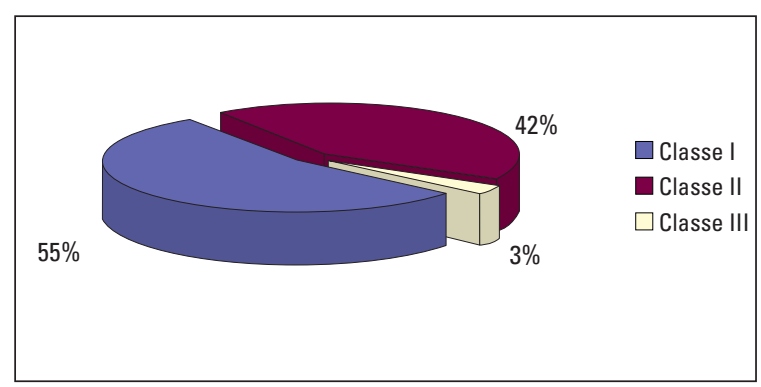

GRÁFICO 5 - Distribuição da relação sagital entre os arcos dentários (Classe I, Classe II e Classe III) encontrada em crianças nos estágios de dentadura decídua ${ }^{27}$ e dentadura mista ${ }^{23}$. Diagnóstico realizado com base na chave de caninos decíduos.

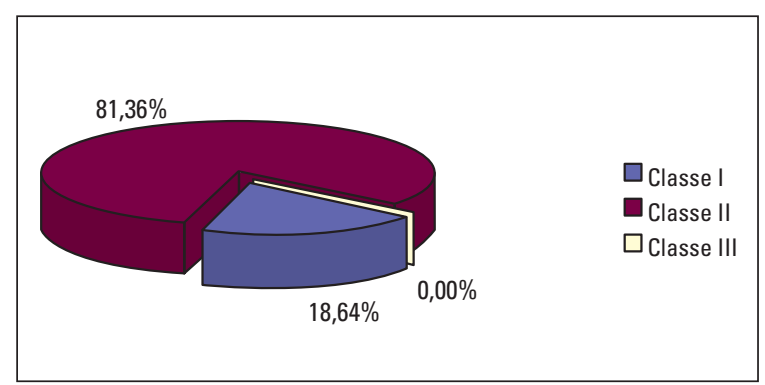

GRÁFICO 7 - Distribuição das Classes entre as crianças com Padrão II $(n=665)$.

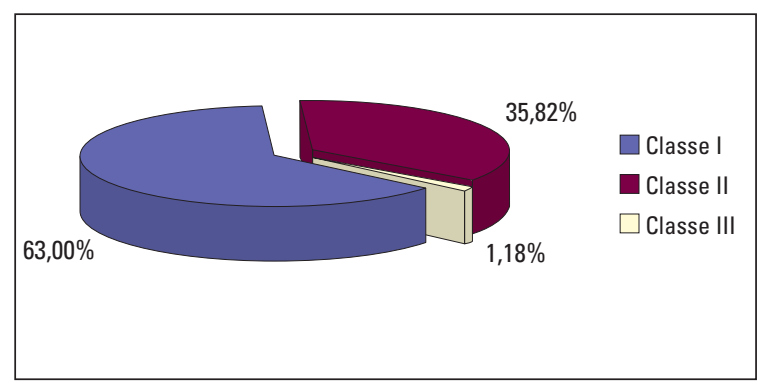

GRÁFICO 6 - Distribuição das Classes entre as crianças com Padrão I $(n=1270)$.

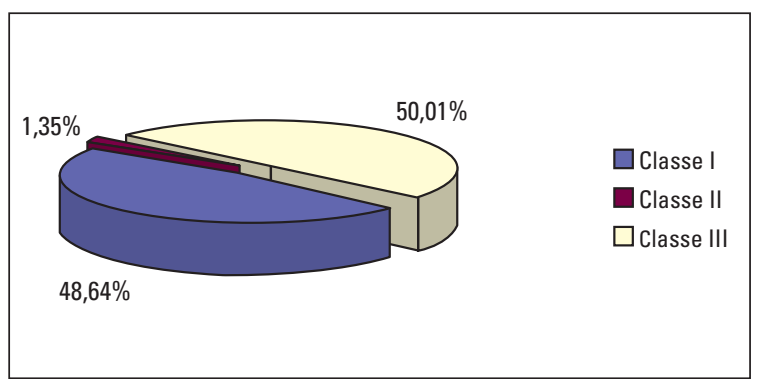

GRÁFICO 8 - Distribuição das Classes entre as crianças com Padrão III $(n=74)$. 
categorias Classe e Padrão, por meio do teste qui-quadrado, sendo que foi encontrada associação significativa entre as Classes e os Padrões, no sentido de que:

- A Classe I foi mais freqüente no Padrão I e menos freqüente no Padrão II;

- A Classe II foi mais freqüente no Padrão II e menos freqüente nos Padrões I e III;

- A Classe III foi mais freqüente no Padrão III, menos freqüente no Padrão I e inexistente no Padrão II.

\section{DISCUSSÃO}

Os resultados obtidos na avaliação lateral da face (Gráf. 1) revelam predomínio de crianças Padrão I $(63,22 \%)$ em relação ao Padrão II $(33,10 \%)$ e ao Padrão III (3,68\%), a despeito da variável sexo (Gráf. 2). O presente levantamento epidemiológico mostra supremacia para o equilíbrio facial encontrado no Padrão I, com uma morfologia apontada como correta e adequada aos conceitos ocidentais de beleza facial. Isso é positivo visto que, via de regra, crianças Padrão I crescem como Padrão I e mantêm-se como Padrão I na maturidade esquelética. As sobreposições cefalométricas em norma lateral e em norma frontal do padrão Bolton ${ }^{6}$ reafirmam essa predisposição morfológica (Fig. 2). Ao se reconhecer o conceito Padrão ${ }^{7}$, admite-se que a face cresce mantendo sua configuração já que obedece a um modelo morfogeneticamente determinado e, tudo indica, pouco influenciado pelos fatores ambientais. Assim, é possível avaliar a face desde a infância, a partir da dentadura decídua completa, quando o tecido adiposo neonatal que mascarava o comportamento esquelético nas idades mais precoces já desapareceu, permitindo aos tecidos moles contornarem com maior fidelidade o arcabouço esquelético. Embora durante a dentadura decídua ainda haja muito crescimento craniofacial por vir, especialmente na mandíbula e no sentido vertical ${ }^{15}$, desvios no padrão de crescimento já podem ser

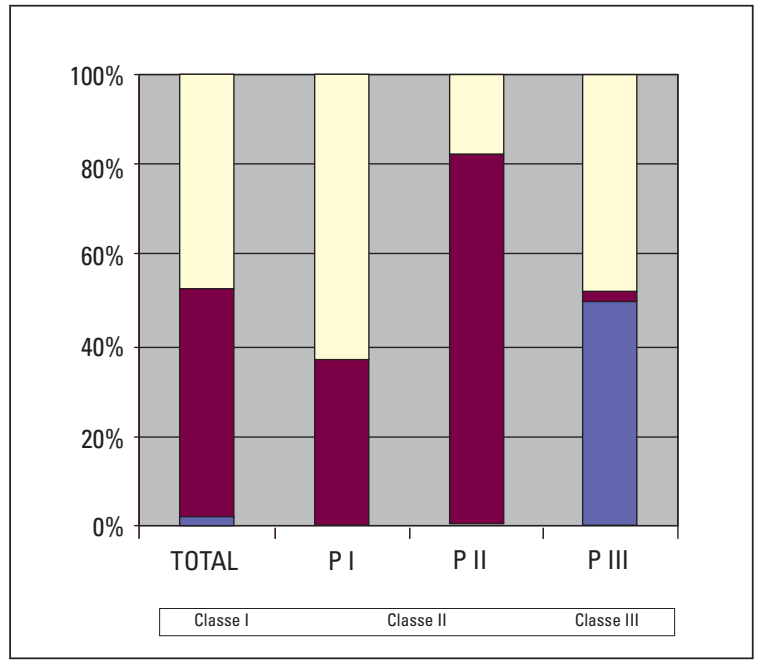

GRÁFICO 9 - Distribuição percentual comparativa das características sagitais da oclusão na amostra total ( $n=2009$ ) e em cada padrão facial (Padrão l, n=1270; Padrão II, n=665; Padrão III, n=74).

Tabela 3 - Distribuição das características sagitais da oclusão na amostra total $(n=2009)$ e em cada Padrão facial ( $\mathrm{Pa}$ drão I, n=1270; Padrão II, n=665 Padrão III, n=74).

\begin{tabular}{ccccc}
\hline & $\begin{array}{c}\text { TOTAL } \\
(\mathrm{n}=2009)\end{array}$ & $\begin{array}{c}\text { Padrão I } \\
(\mathrm{n}=1270)\end{array}$ & $\begin{array}{c}\text { Padrão II } \\
(\mathrm{n}=665)\end{array}$ & $\begin{array}{c}\text { Padrão III } \\
(\mathrm{n}=74)\end{array}$ \\
\hline Classe I & 960 & 800 & 124 & $36(48,64 \%)$ \\
& $(47,78 \%)$ & $(62,99 \%)$ & $(18,64 \%)$ & \\
Classe II & 997 & 455 & 541 & $1(1,35 \%)$ \\
& $(49,62 \%)$ & $(35,82 \%)$ & $(81,35 \%)$ & \\
Classe III & $52(2,58 \%)$ & $15(1,18 \%)$ & - & $37(50,00 \%)$ \\
\hline
\end{tabular}

Tabela 4 - Distribuição das características sagitais da oclusão na amostra total ( $n=2009)$ e dentro de cada Padrão facial (Padrão I, n=1270; Padrão II, n=665 Padrão III, n=74), discriminados por sexo.

\begin{tabular}{cccccc}
\hline & & $\begin{array}{c}\text { TOTAL } \\
(\mathrm{n}=2009)\end{array}$ & $\begin{array}{c}\text { Padrão I } \\
(\mathrm{n}=1270)\end{array}$ & $\begin{array}{c}\text { Padrão II } \\
(\mathrm{n}=665)\end{array}$ & $\begin{array}{c}\text { Padrão } \\
\text { III (n=74) }\end{array}$ \\
\hline 0 & Classe I & 502 & 414 & 73 & 15 \\
1027 & & $(48,88 \%)$ & $(64,99 \%)$ & $(20,50 \%)$ & $(44,11 \%)$ \\
$(51,11 \%)$ & Classe II & 500 & 217 & 283 & - \\
& & $(48,68 \%)$ & $(34,06 \%)$ & $(79,49 \%)$ & \\
& Classe III & 25 & $6(0,94 \%)$ & - & 19 \\
& & $(2,43 \%)$ & & & $(55,88 \%)$ \\
9 & Classe I & 458 & 386 & 51 & 21 \\
982 & & $(46,63 \%)$ & $(60,97 \%)$ & $(16,50 \%)$ & $(52,50 \%)$ \\
$(48,88 \%)$ & & & & & \\
& Classe II & 497 & 238 & 258 & $1(2,50 \%)$ \\
& & $(50,61 \%)$ & $(37,59 \%)$ & $(83,49 \%)$ & \\
& Classe III & 27 & $9(1,42 \%)$ & - & 18 \\
& & $(2,74 \%)$ & & & $(45,00 \%)$ \\
\hline
\end{tabular}



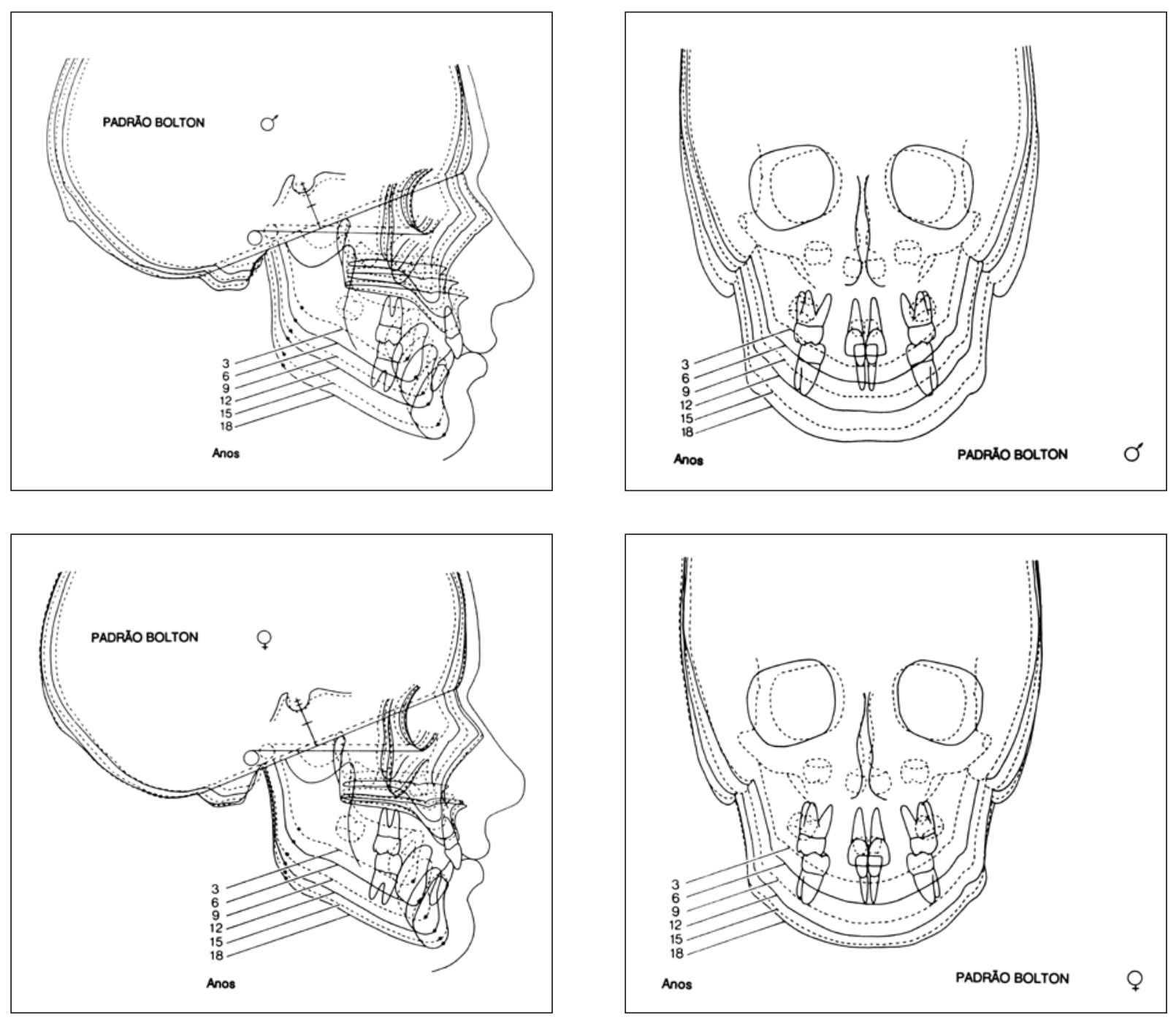

FIGURA 2 - Sobreposição cefalométrica seriada e longitudinal, extraída do estudo padrão Bolton, para os sexos masculino (A e B) e feminino (C e D).

identificados e nos remeter a protocolos interceptivos na tentativa de restabelecer um ambiente morfológico propício para a tentativa de adequação do crescimento craniofacial.

Quase dois terços das crianças avaliadas, exatamente $63,22 \%$, não exibiram discrepâncias esqueléticas sagitais (Gráf. 1). Nessas crianças, o prognóstico de tratamento, quando houver má oclusão, tende a ser favorável, posto que a correção envolve dentes, sem pretensão ortopédica. Dos 37\% das crianças que apresentavam erro sagital na face, 33\% mostraram morfologia facial compatível com o Padrão II e próximo de 4\%, com o Padrão III (Gráf. 1). A caracterização dos Padrões faciais II e III sugere correção das bases apicais, maxila e mandíbula, no intento de melhorar a configuração facial. Existem abordagens ortopédicas voltadas para a correção do erro esquelético, quando ainda há crescimento. A aplicação de tratamentos ortopédicos precoces oferece a oportunidade de se estabelecer uma relação mais próxima do normal entre os 
componentes esqueléticos, normalizando a relação entre os arcos dentários, ou seja, a Classe. De fato, a prática demonstra ser mais fácil a correção da Classe do que do Padrão.

Uma coisa é certa, a aplicação de ortopedia para os Padrões II e III está condicionada à condição oclusal. Isso significa que é possível recorrer à abordagem ortopédica para a deficiência mandibular, no Padrão II, se a oclusão permitir. $\mathrm{O}$ avanço mandibular ortopédico é viabilizado nas más oclusões Classe II com trespasse horizontal aumentado. No Padrão III, a tração reversa da maxila deve ser aplicada na presença de mordida cruzada anterior, de preferência acompanhada de relação Classe III. Portanto, no diagnóstico, interessa para o ortodontista a relação basal e a relação oclusal, isto é, esqueleto e dentes. Não é possível arquitetar um plano de tratamento ignorando um desses dois componentes, face e oclusão. A inter-relação entre desenvolvimento da oclusão e crescimento e morfologia craniofacial é um tópico popular entre os pesquisadores em Ortodontia, no entanto, é raro essa correlação usando metodologia clínica, como esta pesquisa, por exemplo, que usa face e dentes avaliados clinicamente.
A experiência clínica mostra que a relação oclusal tende a refletir o padrão facial, embora isso não seja verdade para todos os casos. Devese considerar que as compensações dentoalveolares podem induzir a padrões de normalidade oclusal, mesmo na presença de desvios da normalidade do Padrão. Os pesquisadores ${ }^{8,13,18}$ têm mencionado que uma oclusão relativamente boa com uma discrepância esquelética não é incomum, da mesma forma que alterações esqueléticas têm sido descritas mesmo em amostras de oclusão normal, confirmando que existem variações anatômicas consideráveis tanto na chamada oclusão normal quanto na má oclusão. Entretanto, aceitando-se o Padrão como fator etiológico primário das más oclusões, as relações sagitais interarcos, definidas pela Classe, são reflexos que a caracterizam ${ }^{7}$. Os resultados aqui obtidos confirmam tal premissa ao demonstrarem que as características oclusais guardam estreita correlação com a configuração morfológica sagital da face humana. As crianças Padrão I possuem predomínio das relações oclusais em Classe I. As crianças com Padrão II mostram predomínio de Classe II e as crianças com Padrão III dividem-se
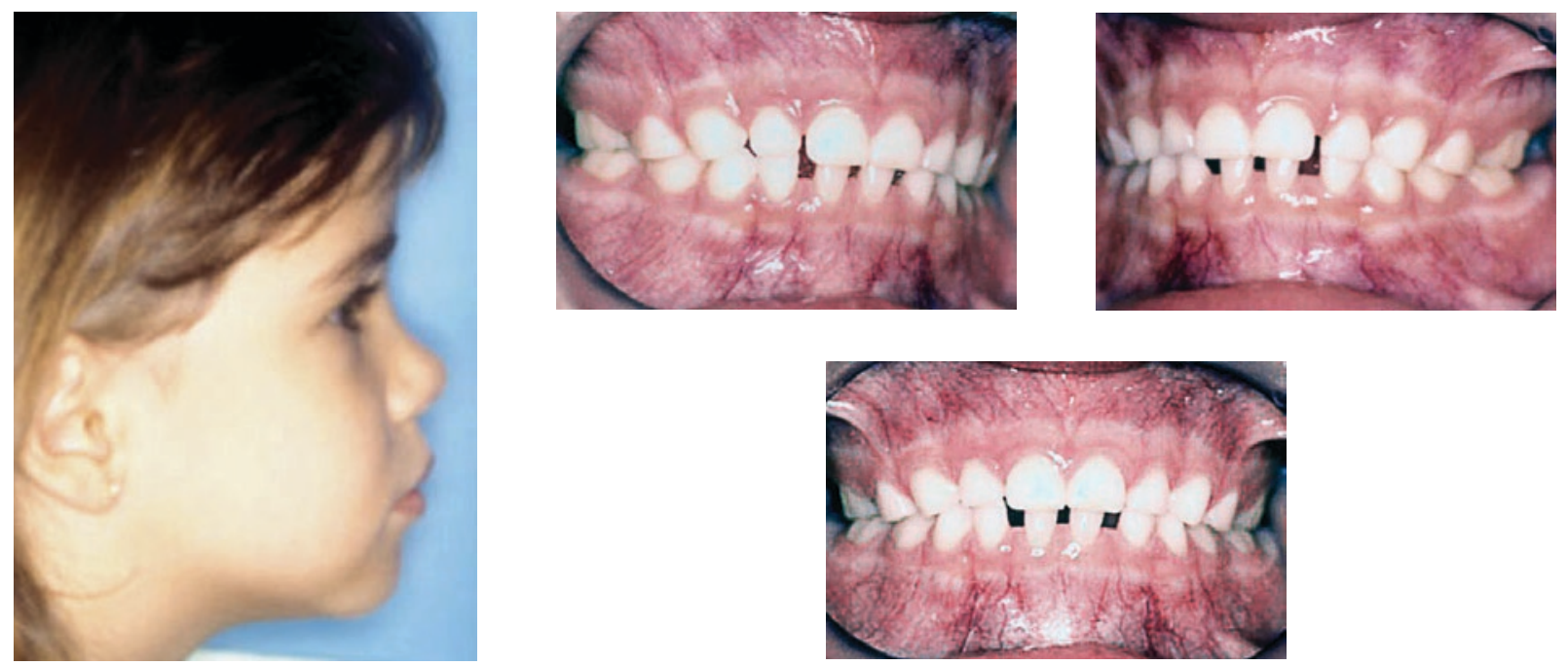

FIGURA 3 - Padrão I, acompanhado de Classe I. 63\% das crianças Padrão I desenvolvem uma oclusão Classe I. 
entre Classe I e Classe III. Avaliando os dados obtidos neste estudo, pode-se concluir que as condições oclusais sagitais, Classes I, II e III, sofrem influência do padrão facial geneticamente determinado.

As crianças Padrão I apresentavam as relações interarcos distribuídas predominantemente em Classe I (62,99\%), conforme ilustrado na figura 3 , seguida pela relação de Classe II $(35,82 \%)$ e Classe III $(1,18 \%)$. A relação sagital de Classe II não é tratada na dentadura decídua. Prefe- rencialmente, o tratamento inicia-se a partir da dentadura mista. Dentro deste padrão facial, a terapia implica em distalização de molares para correção da relação interarcos e para aumento do perímetro do arco dentário superior ou em extração de dentes. A decisão terapêutica depende da presença de apinhamento no arco dentário superior ou em ambos os arcos dentários. Qualquer que seja a opção terapêutica, o tratamento independe de crescimento. Como regra geral, o tratamento da má oclusão dentro
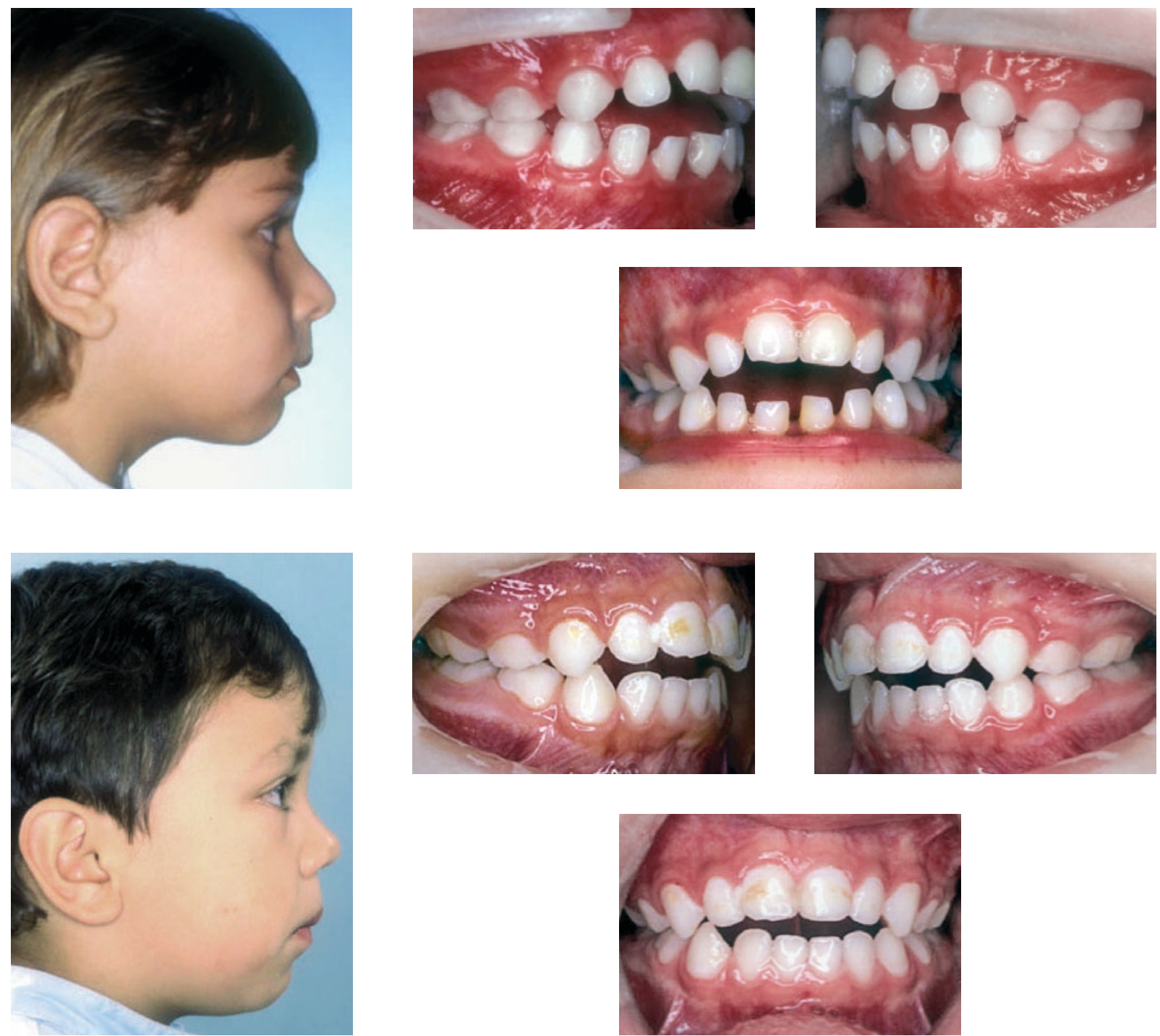

FIGURA 4 - Padrão II, acompanhado de más oclusões Classe II. Mais de 80\% das crianças Padrão II desenvolvem uma oclusão Classe II. 

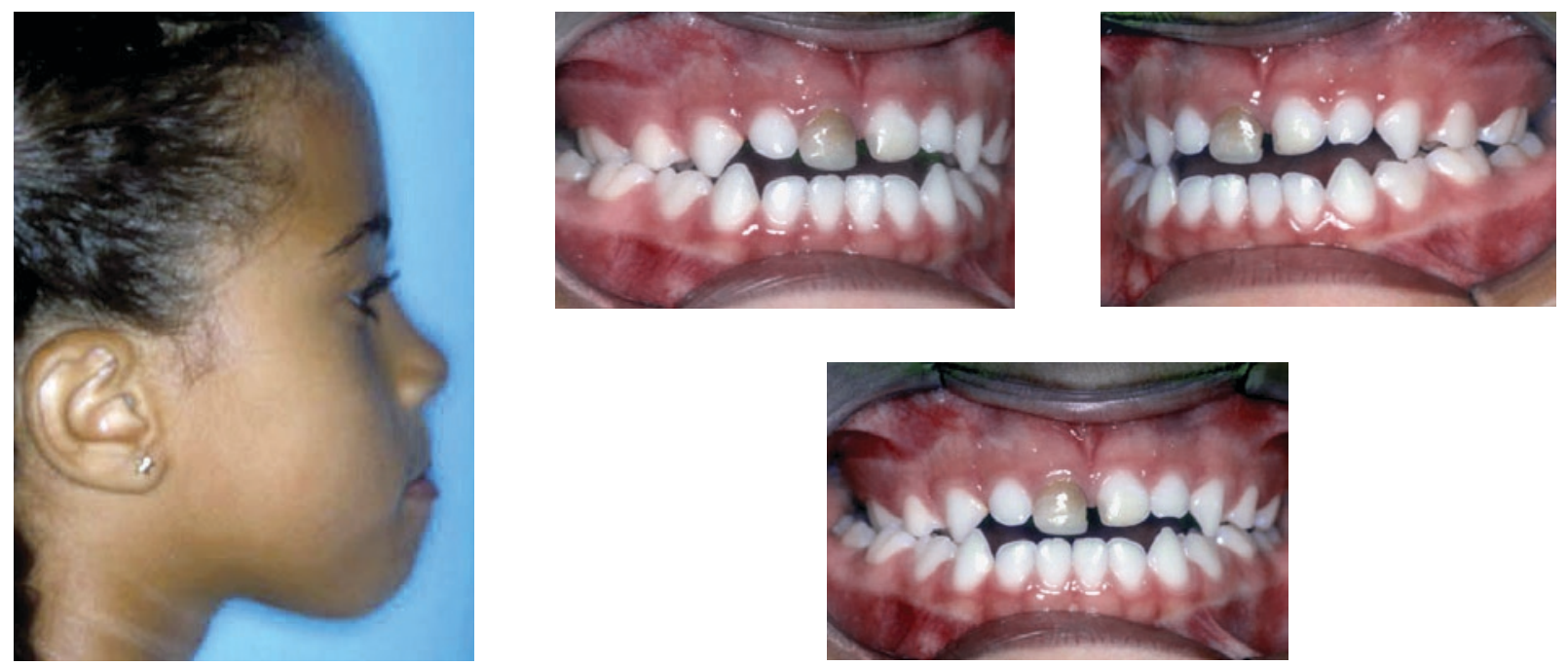

FIGURA 5 - Padrão III, acompanhado de má oclusão Classe III. 50\% das crianças Padrão III desenvolvem uma oclusão Classe III.

do Padrão I não influencia o crescimento facial. Por outro lado, a Classe III pode ser tratada com expansão rápida e tração reversa da maxila, já na dentadura decídua ${ }^{26}$.

As crianças com Padrão II mostraram uma relação interarcos mais homogênea, com predomínio da relação de Classe II $(81,35 \%)$, conforme exemplificado na figura 4, e não apresentaram relação de Classe III. Essa relação de Classe II possibilita o tratamento do padrão, com ortopedia de avanço mandibular. A deficiência mandibular não é tratada na dentadura decídua. O protocolo de tratamento do Padrão II pode ser feito nos estágios iniciais da dentadura mista, no protocolo precoce, ou na adolescência, que corresponde ao final da dentadura mista, ou na dentadura permanente, no protocolo de tratamento tardio ${ }^{28}$. A relação positiva entre convexidade do perfil facial e relação oclusal de Classe II já havia sido demonstrada na literatura ${ }^{2}$.

As crianças Padrão III apresentaram predomínio de Classe III (Fig. 5), mas tiveram uma distribuição mais heterogênea em relação às crianças Padrão II. 48\% das crianças apresen- tavam Classe I e um número inexpressivo de 1,35\%, Classe II. Nesses casos, o tratamento ortopédico indicado seria a tração reversa da maxila ${ }^{25,26}$, associada à contenção com mentoneira, por algum tempo, a ser decidido principalmente pela gravidade da discrepância e pelo comportamento da face diante do tratamento ortopédico. As crianças Classe I e Padrão III, com o crescimento podem desenvolver relação sagital de Classe III. Se a Classe I persistir ao longo do crescimento, elas podem ser tratadas com cirurgia ortognática, depois de transformadas em Classe III, com o tratamento ortodôntico descompensatório, ou simplesmente pela mudança de inclinação do plano oclusal. É possível tratar o Padrão III, Classe I com ortopedia em idade precoce. O problema é que depois do tratamento, se bem sucedido, a Classe I passa para Classe II. A Classe II no Padrão III é circunstancial e muito provavelmente decorrente de atresia do arco dentário superior. Provavelmente deve-se a uma questão simplesmente geométrica entre os arcos dentários.

Em síntese, nota-se que o posicionamento dos dentes na maioria dos casos é conseqüên- 
cia do erro esquelético que caracteriza a má oclusão. Essa correlação prediz quais serão os problemas dentários que os portadores dos diferentes tipos de padrão tenderão a apresentar. Fazer essa avaliação precocemente, entendendo como o crescimento vai se processar, implica em definir as possibilidades reais e coerentes de tratamento, com um prognóstico mais realista e estável.

\section{CONCLUSÃO}

A expectativa clínica se comprovou. Há uma tendência definitiva das relações oclusais, as Classes, acompanharem o Padrão facial, desde o estágio de dentadura decídua, embora a oclusão possa guardar alguma independência do Padrão. A maior heterogeneidade na distribuição das classes ficou para os Padrões I e III. No Padrão II, a relação interarcos se comportou de forma mais homogênea, já que mais de $80 \%$ das crianças deste grupo apresentaram relação de Classe II.

\title{
Correlation between facial pattern and sagittal relationship between dental arches in deciduous dentition: epidemiological considerations
}

\begin{abstract}
The interrelationship between occlusion and facial morphology is fundamental for diagnosis and planning in Orthodontics. In general, the sagittal relationship between dental arches (Class) tends to reflect the sagittal position of facial skeleton (Pattern). This current paper assesses the correlation between sagittal facial morphological characteristics (Pattern) and occlusion (Class) in deciduous dentition. The sample was comprised of 2009 children aged between 3 and 6 years, in the complete deciduous dentition, from 20 pre-schools in Bauru - SP. The results showed a statiscally significant correlation between the facial Pattern and Class. In Pattern I, Class I children predominated (62.99\%), followed by Class II (35.82\%) and Class III (1.18\%). In Pattern II, Class II children were predominant (81.35\%), followed by a low incidence of Class I (18.64\%). In Pattern III, Class III was found in $50.00 \%$ of children, followed by Class I (48.64\%) and Class II (1.35\%). The expectation has been confirmed. There is a tendency of Class to reflect facial Pattern, starting from deciduous dentition stage. It was more explicit in Pattern II. The results also clarify that occlusion may differ from the Pattern. Patterns I and III showed the greatest heterogeneity in the distribution of Classes. In Pattern II, the Classes were more homogeneous; more than $80 \%$ of children in this group presented Class II relationship.
\end{abstract}

Key words: Face. Occlusion. Tooth deciduous. Epidemiology.

\section{REFERÊNCIAS}

1. ABU ALHAIJA, E. S.; RICHARDSON, A. Growth prediction in Class III patients using cluster and discriminate function analysis. Eur. J. Orthod., Oxford, v. 25, no. 6, p. 599-608, Dec. 2003.

2. ALEXANDER, S.; PRABHU, N. T. Profiles, occlusal planes relationships and spacing of teeth in the dentitions of 3 to 4 year old children. J. Clin. Pediatr. Dent., Birmingham, v. 22, no. 4, p. 329-334, Summer 1998.

3. ANGLE, E. H. Malocclusion of the teeth. 7th ed. Philadelphia: White Dental, 1907.
4. BISHARA, S. E.; JAKOBSEN, J. R. Longitudinal changes in three normal facial types. Am. J. Orthod. Dentofacial Orthop., St. Louis, v. 88, no. 6, p. 466-502, Dec 1985.

5. BITTNER, C.; PANCHERZ, H. Facial morphology and malocclusions. Am. J. Orthod. Dentofacial Orthop., St. Louis, v. 97, no. 4, p. 308-315, Apr. 1990.

6. BROADBENT, B. H.; BROADBENT JR., B. H.; GOLDEN, W. H. Bolton standards of dentofacial developmental growth. St. Louis: C. V. Mosby, 1975. 
7. CAPELOZZA FILHO, L. Diagnóstico em Ortodontia. Maringá: Dental Press, 2004.

8. CASCO, J. S.; SHEPARD, W. B. Dental and skeletal variation within the range of normal. Angle Orthod., Appleton, v. 54, no. 1, p. 5-17, Jan. 1984.

9. CASE, C. A practical treatise on the techniques and principals of dental orthopedia and correction of cleft palate. 2nd ed. Chicago: Case Company, 1922.

10. CHANG, H.; KINOSHITA, Z.; KAWAMOTO, T. Craniofacial pattern of Class III deciduous dentition. Angle Orthod. Appleton, v. 62, no. 2, p. 139-144, Summer 1992.

11. CHEVITARESE, A. B. A.; VALLE, D. D.; MOREIRA, T. C. Prevalence of malloclusion in 4-6 year old Brazilian children. J. Clin. Pediatr. Dent., Birminghan, v. 27, no. 1, p. 81-86, Fall 2002

12. DIBBETS, J. M. H. Morphological associations between the Angle classes. Eur. J. Orthod., London, v. 18, no. 2, p. 111-118, Apr. 1996.

13. FISHMAN, L. S. Individualizad evaluation of facial form. Am. J. Orthod. Dentofacial Orthop., St. Louis, v. 111, no. 5 , p. 510-517, May 1997.

14. HALAZONETIS, D. J. Estimated natural head position and facial morphology. Am. J. Orthod. Dentofacial Orthop., St. Louis, v. 121, no. 4, p. 364-368, Apr. 2002.

15. JAMISON, J. et al. Longitudinal changes in the maxilla and the maxillary-mandibular relationship between 8 and 17 years of age. Am. J. Orthod., St. Louis, v. 82, no. 3, p. 217-220, Sept. 1982.

16. KEELING, S. D. et al. A multivariate approach to analyzing the relation between occlusion and craniofacial morphology. Am. J. Orthod. Dentofacial Orthop., St. Louis, v. 95, no. 4, p. 297-305, Apr. 1989.

17. KERR, W. J.; HIRST, D. Craniofacial characteristics of subjects with normal and postnormal occlusions - a longitudinal study. Am. J. Orthod. Dentofacial Orthop., St. Louis, v. 92, no. 3, p. 207-212, Sept. 1987.

18. KIM, J. Y. et al. Classification of the skeletal variation in normal occlusion. Angle Orthod., Appleton, v. 75, no. 3, p. 311-319, May 2005.

19. LUNDSTRÖM, A. et al. Natural head position and natural head orientation: basic considerations in cephalometric analysis and research. Eur. J. Orthod., Oxford, v. 17, no. 2, p. 111-120, Apr. 1995.

20. MARTINS, J. C. R. et al. Prevalência de má-oclusão em préescolares de Araraquara: relação da dentição decídua com hábitos e nível sócio-econômico. Rev. Dental Press Ortodon. Ortop. Facial, Maringá, v. 3, n. 6, p. 35-43, nov./dez. 1998.

21. MOORREES, C. F. A. Natural head position: a revival. Am. J. Orthod. Dentofacial Orthop., St. Louis, v. 105, no. 5, p. 512-513, May 1994.
22. RINO NETO, J.; FREIRE-MAIA, B. A.: PAIVA, J. B. Método de registro da posição natural da cabeça para obtenção da radiografia cefalométrica lateral: considerações e importância do método no diagnóstico ortodôntico-cirúrgico. Rev. Dental Press Ortodon. Ortop. Facial, Maringá, v. 8, no. 3, p. 61-71, maio/jun. 2003.

23. SILVA FILHO, O. G. FREITAS, S. F: CAVASSAN, A. O Prevalência de oclusão normal e má-oclusão na dentadura mista em escolares da cidade de Bauru (São Paulo). Parte l: relação sagital. Rev. Odontol. USP., São Paulo, v. 4, n. 2, p. 130-137, abr./jun. 1990.

24. SILVA FILHO, O. G.; HERKRATH, F. J.; QUEIROZ, A. P. AIELLO, C. A. Padrão facial na dentadura decídua: estudo epidemiológico. Rev. Dental Press Ortodon. Ortop. Facial, Maringá, 2006. No prelo.

25. SILVA FILHO, O. G.; MAGRO, A. C.; OZAWA, T. O. Má oclusão de classe III: caracterização morfológica na infância (dentaduras decídua e mista). Ortodontia, São Paulo, v. 30, n. 2, p. 7-20, mar./ago. 1997.

26. SILVA FILHO, O. G.; MAGRO, A. C.; CAPELOZZA FILHO L. Early treatment of the class III malocclusion with rapid maxillary expansion and maxillary protraction. Am. J. Orthod. Dentofacial Orthop., St. Louis, v. 113, no. 2, p.196-203, Feb. 1998

27. SILVA FILHO, O. G. et al. Epidemiologia da má-oclusão na dentadura decídua. Ortodontia, São Paulo, v. 35, n. 1 p. 22-23, jan./mar. 2002.

28. SILVA FILHO, O. G.; AIELLO, C. A.; FONTES, M. V. Aparelho Herbst: protocolos de tratamento precoce e tardio. Rev. Dental Press Ortodon. Ortop. Facial, Maringá, v. 10, n. 1, p. 30-45, jan./fev. 2005

29. SINGH, G. D.; McNAMARA JR., J. A.; LOZANOFF, S. Finiteelement morphometry of soft tissue morphology in subjects with untreated Class III malocclusions. Angle Orthod., Appleton, v. 69, no. 3, p. 215-224, June 1999.

30. TOLLARO, I. et al. Class III malocclusion in the deciduous dentition: a morfological and correlation study. Eur. J. Orthod., Oxford, v. 16, no. 5, p. 401-408, Oct. 1994.

31. TROTTMAN, A.; MARTINEZ, N. P.; ELSBACH, H. G. Occlusal disharmonies in the primary dentitions of black and white children. ASDC J. Dent. Child., Chicago, v. 66, no. 5 p. 332-336, Sept./Oct. 1999

32. WILLIAMS, S.; ANDERSEN, C. E. The morphology of the potential Class III skeletal pattern in the growing child. Am. J. Orthod., St. Louis, v. 89, no. 4, p. 302-311, Apr. 1986.

\author{
Endereço de correspondência \\ Omar Gabriel da Silva Filho \\ Rua Silvio Marchione, 3-20, Vila Universitária \\ CEP: 17.043-900 - Bauru / SP \\ E-mail: clinica_esteves@yahoo.com.br
}

